\title{
ANÁLISE DO ENSINO DE TEORIA ECONÔMICA NOS CURSOS DE ENGENHARIA DE PRODUÇÃO EM SEUS ASPECTOS CURRICULARES ${ }^{1}$
}

\section{ANALYSIS OF CURRICULAR ASPECTS OF ECONOMICS' TEACHING IN INDUSTRIAL ENGINEERING COURSES}

\author{
Antonio Marcos Rodrigues e Silva*E-mail: hammer-on@bol.com.br \\ Rita de Cássia Magalhães Trindade Stano*E-mail: trindade@unifei.edu.br \\ Marcelo Lacerda Rezende** E-mail: marcelo.rezende@unifal-mg.edu.br \\ *Universidade Federal de Itajubá, UNIFEI, Itajubá, MG \\ ** Universidade Federal de Alfenas, UNIFAL, Alfenas, MG
}

\begin{abstract}
Resumo: A Engenharia de Produção é uma das áreas que tem chamado a atenção, especialmente por sua sinergia com outros ramos do saber. Pensar a educação em Engenharia de produção passa, necessariamente, pelo pensar em seu relacionamento e interdependência com as demais áreas afins. Neste sentido, coloca-se a sua relação com a Ciência Econômica. Apesar de os objetivos das duas ciências e seus métodos serem distintos, se tocam em muitos pontos. Assim, a contribuição do estudo de Economia está diretamente associada ao modo como serão trabalhados tais conteúdos nos cursos de Engenharia de Produção, passando, inclusive pela escolha desses conteúdos a serem cobertos nos cursos. Motivado pelo exposto, o objetivo do presente trabalho é analisar o ensino de Economia nos cursos de Engenharia de Produção no Brasil. Para tanto, foi realizada uma pesquisa documental, com a utilização da Análise de Conteúdo dos Planos de Ensino das disciplinas ligadas à Economia dos cursos de 15 Instituições. Verificou-se que os conteúdos trabalhados são abrangentes, com ênfase para as disciplinas com maior conteúdo teórico da Ciência Econômica. Porém, a forma de trabalhá-los, bem como a maneira como os alunos são avaliados, ainda é de caráter tradicional.
\end{abstract}

Palavras chaves: Ensino de Economia. Ensino de Engenharia de Produção. Pesquisa documental. Análise de conteúdo. Planos de Ensino.

Abstract: Industrial Engineering is a field that has attracted the attention, especially because of its synergy with other areas of knowledge. In order to think about education in Industrial Engineering it is necessary to consider its relationship and interdependence with other areas. In this way, the relationship with Economics is considered. Although the objectives of both areas and their methods are distinct, they are related in many points. So, the contribution of study economy is directly related to the ways these topics will be studied in the Industrial Engineering courses. It is also implied how these topics will be chosen to be presented. The present paper's objective is to analyze the teaching of Economics in the Industrial Engineering courses in Brazil. In order to achieve this objective, a documental research has been conducted, using the Content Analysis technique applied to the Teaching Plans of the disciplines covering the Economics contents in 15 Institutions. It has been concluded that the topics covered in the courses are of a broad nature, with emphasis in theoretic content of Economics. Furthermore, the strategies used in classroom, as well as the assessment methods are still of traditional nature.

Keywords: Economics teaching; Industrial Engineering teaching; documental research; content analysis; Teaching Plans.

\footnotetext{
${ }^{1}$ Artigo elaborado com base na dissertação, de mesmo título, defendida pelo primeiro autor.
} 


\section{INTRODUÇÃO}

No início dos anos 2000, algumas mudanças ocorreram na legislação pertinente à formação e exercício profissional do Engenheiro, de modo a evidenciar sua evolução e seu maior grau de complexidade. Tais mudanças refletiram-se na maneira como os cursos de Engenharia são estruturados. Até então, a legislação era mais rígida na determinação do currículo e das cargas horárias a serem cumpridas, deixando de ressaltar vocações provenientes da realidade regional onde os cursos de Engenharia se inseriam e dando menos liberdade às instituições de ensino na concepção e planejamento de seus cursos. Apesar disso, o aparato legal atualmente em vigor procura abordar desde a formação do Engenheiro, quanto ao projeto pedagógico de sua instituição, até as disciplinas a serem estudadas, dispondo sobre carga horária e tempo mínimo para conclusão do curso, incluindo a definição e regulamentação das atividades do profissional, sua titulação, obrigações e direitos.

A determinação legal atual para a formação acadêmica de um Engenheiro exige que conteúdos pertencentes a outros ramos, como as Ciências Sociais, sejam contemplados. A Resolução CNE/CES 11/2002 (BRASIL, 2002) estabelece que o egresso de um curso de Engenharia deve possuir um perfil generalista, humanista e que seja apto a resolver problemas, levando em conta aspectos econômicos, políticos, sociais, culturais e ambientais, de modo que trabalhe em prol da sociedade. Quanto ao Engenheiro de Produção, seu campo de atuação profissional envolve, dentre outras, atividades ligadas à organização industrial, avaliação e estratégias de mercado, redes de empresas, cadeias produtivas, gestão financeira de projetos e gestão de custos e investimentos.

O cruzamento das fronteiras que delimitam os diversos campos do conhecimento é necessário ao profissional da Engenharia de Produção, visto que se deparará com problemas com grau de subjetividade muito maior do tradicionalmente encontrado nas ciências exatas. Nesse contexto, o estudo da Teoria Econômica poderá contribuir para a formação do Engenheiro de Produção, para que possa desempenhar plenamente suas atividades profissionais, uma vez que as atividades já destacadas exigirão competências e habilidades relativas a esta área.

Diante desta realidade, alguns fatos devem ser pontuados. Primeiramente, há a exigência legal (Resolução CONFEA 1.010/2005) para que o estudo da Teoria 
Econômica seja incluído na formação do Engenheiro de Produção, evidenciando a realidade atual de sua atuação profissional. A Teoria Econômica, como ciência social aplicada, possui um escopo amplo. A natureza dos problemas objeto de sua investigação muitas vezes não tem um contorno bem definido. Por outro lado, a compreensão dos seus fundamentos pode contribuir para o entendimento da maneira como as empresas atuam em diferentes mercados e as forças as quais estão submetidas. A contribuição desse estudo também é evidente para a formação cidadã do futuro profissional, na medida em que este compreenda a natureza e os contornos dos problemas econômicos, a atuação governamental, por meio da política econômica, bem como os impactos econômicos e ambientais de determinados projetos.

Estes fatos motivaram a presente pesquisa, que teve por objetivo analisar de que maneiras têm-se realizado o ensino de Economia nos cursos de Engenharia de Produção. Foram explorados alguns aspectos do assunto, tais como a definição do currículo que deverá cobrir os conteúdos da Economia, a carga horária a ser dedicada à(s) disciplina(s) e a maneira como tais disciplinas são conduzidas nos cursos de Engenharia de Produção.

\section{MATERIAIS E MÉTODOS}

Para atender ao objetivo proposto no presente trabalho, optou-se pela realização de uma pesquisa documental, analisando-se os planos de ensino das disciplinas relacionadas à Teoria Econômica, em diferentes instituições de ensino. De acordo com Marconi e Lakatos (1999) a pesquisa documental caracteriza-se pela fonte de coleta de dados ser restrita a documentos, escritos ou não, constituindo-se o que se chama de fontes primárias.

A análise dos dados obtidos constitui-se na Análise de Conteúdo, que é um conjunto de técnicas de análise qualitativa que busca dar tratamento quantitativo aos dados. Nessa análise é feita a contagem de freqüência dos fenômenos, procurandose identificar possíveis relações entre eles (DIEHL e TATIM, 2004). Para isso foram utilizados modelos conceituais a priori na interpretação dos dados, isto é, buscandose na literatura as categorias de análise, conforme proposto por Cortes (2002).

Os passos seguidos nesta pesquisa foram: revisão bibliográfica; análise da 
legislação; avaliação das grades curriculares dos cursos pesquisados, para identificar que disciplinas cobrem conteúdos próprios da Teoria Econômica; coleta de dados (Planos de Ensino) dos cursos a serem analisados; análise de conteúdo dos documentos coletados; análise e discussão de resultados.

A seleção das instituições para análise nesta pesquisa constituiu-se em uma amostra intencional onde, conforme Marconi e Lakatos (1999), o foco dos pesquisadores se dirigiu a determinados elementos da população que desempenham a função de líderes de opinião na comunidade, muito embora não sejam elementos representativos da população em geral.

Um dos critérios utilizados para a identificação de cursos selecionados para análise foi o Exame Nacional de Desempenho dos Estudantes (ENADE), um dos instrumentos do Sistema Nacional de Avaliação da Educação Superior (SINAES) e que foi instituído pela lei número 10.861, de 14 de abril de 2004. O teste foi aplicado pela primeira vez em 6 de Novembro de 2005. A Engenharia de Produção compõe, no contexto do ENADE, a área de Engenharia Grupo VI. A avaliação dos estudantes em termos dos seus perfis profissionais e das suas habilidades gerou um resultado final para cada instituição/curso. Estes resultados são traduzidos por meio de um conceito numérico, que vai de 1 a 5 , atribuído conforme duas vertentes: formação geral, que vale $25 \%$ do conceito, que não discrimina ingressantes e concluintes, e componente específico, valendo $75 \%$ do conceito, sendo $15 \%$ relativos aos ingressantes e $60 \%$ dos concluintes (INEP, 2005).

Entre os selecionados, há cursos que não receberam um conceito por não contarem com alunos ingressantes ou concluintes (INEP, 2005). Igualmente, a Universidade de São Paulo - USP absteve-se de participar do exame, conforme divulgado na época pelos meios de comunicação (FOLHA DE SÃO PAULO, 2008), mas foi incluída nesta pesquisa, por se tratar de instituição tradicional no ensino de Engenharia de Produção (PIRATELLI, 2005).

A primeira categoria analisada nos Planos de Ensino foi os objetivos enunciados para as disciplinas, tomando-se como base a Taxonomia de Bloom. Para Belhot (2005), a taxonomia de Bloom, publicada em 1972 e apresentada no Quadro 1, possui dois aspectos que podem ser incorporados ao ensino de Engenharia. $O$ primeiro é a mudança do foco para o aluno, no sentido de declarar os objetivos instrucionais para o mesmo, respondendo à pergunta: "o que o aluno será capaz de 
fazer ou demonstrar, após um determinado tópico ou programa?" O segundo, diz respeito aos níveis de competência desejados, em sintonia com o objetivo específico de uma dada disciplina, e da disciplina em relação ao curso.

Quadro 1 - Níveis da Taxonomia de Bloom e objetivos associados.

\begin{tabular}{|c|c|c|}
\hline Competência & Capacidade a demonstrar & Objetivos associados \\
\hline Conhecimento & $\begin{array}{l}\text { - Observar e lembrar das informações. } \\
\text { - Conhecimento de datas, eventos, } \\
\text { lugares. } \\
\text { - Conhecimento de princípios e } \\
\text { convenções. } \\
\text { - Domínio do assunto tratado }\end{array}$ & $\begin{array}{l}\text { Listar, definir, contar, } \\
\text { descrever, identificar, } \\
\text { mostrar, classificar, coletar, } \\
\text { examinar, tabular, nomear, } \\
\text { quem, onde, quando. }\end{array}$ \\
\hline Compreensão & $\begin{array}{l}\text { - Entender a informação. } \\
\text { - Compreender o significado. } \\
\text { - Interpretar fatos, comparar, contrastar. } \\
\text { - Traduzir conhecimento para novos } \\
\text { contextos } \\
\text { - Ordenar, agrupar, inferir causas. } \\
\text { - Predizer conseqüências. }\end{array}$ & $\begin{array}{l}\text { Sumarizar, descrever, } \\
\text { interpretar, contrastar, } \\
\text { predizer, associar, distinguir, } \\
\text { estimar, diferenciar, discutir, } \\
\text { estender. }\end{array}$ \\
\hline Aplicação & $\begin{array}{l}\text { - Usar informação. } \\
\text { - Usar métodos, conceitos, teorias em } \\
\text { situações novas. } \\
\text { - Resolver problemas usando } \\
\text { competências ou conhecimento. }\end{array}$ & $\begin{array}{l}\text { Aplicar, demonstrar, calcular, } \\
\text { completar, ilustrar, mostrar, } \\
\text { resolver, examinar, modificar, } \\
\text { relacionar, mudar, classificar, } \\
\text { experimentar. }\end{array}$ \\
\hline Análise & $\begin{array}{l}\text { - Reconhecer padrões. } \\
\text { - Organização de partes. } \\
\text { - Percepção de significados ocultos } \\
\text { - Identificação de componentes }\end{array}$ & $\begin{array}{l}\text { Analisar, separar, ordenar, } \\
\text { explicar, conectar, classificar, } \\
\text { arranjar, dividir, comparar, } \\
\text { selecionar, inferir. }\end{array}$ \\
\hline Síntese & $\begin{array}{l}\text { - Usar idéias antigas para criar novas. } \\
\text { - Generalizar a partir de fatos. } \\
\text { - Relacionar conhecimentos de diversas } \\
\text { áreas } \\
\text { - Predizer, derivar conclusões. }\end{array}$ & $\begin{array}{l}\text { Combinar, integrar, } \\
\text { modificar, rearranjar, } \\
\text { substituir, planejar, criar, } \\
\text { projetar, inventar, compor, } \\
\text { formular, preparar, } \\
\text { generalizar, reescrever. }\end{array}$ \\
\hline
\end{tabular}

Fonte: Belhot (2005).

A seguir, em relação às disciplinas, foram analisadas as estratégias de ensino, as formas de avaliação, seus conteúdos e a bibliografia sugerida aos alunos. O Quadro 2 apresenta as instituições de ensino superior cujos cursos de Engenharia de Produção foram selecionados para análise nesta pesquisa. São também apresentadas as respectivas disciplinas que cobrem os conteúdos relativos à Teoria Econômica nos cursos.

Quadro 2 - Instituições e disciplinas que abordam a Economia nos cursos de Engenharia de Revista Produção Online, Florianópolis, SC, v.12, n. 2, p. 480-498, abr./jun. 2012. 


\begin{tabular}{|c|c|}
\hline $\begin{array}{l}\text { Produção } \\
\text { NOME DA INSTITUICCÃO }\end{array}$ & NOME DA DISCIPLINA \\
\hline $\begin{array}{l}\text { FSA - Fundação Santo André } \\
\text { MACK - Universidade Presbiteriana Mackenzie }\end{array}$ & $\begin{array}{l}\text { Economia e Mercado } \\
\text { Economia Industrial } \\
\text { Economia Brasileira } \\
\text { Economia I } \\
\text { Economia II }\end{array}$ \\
\hline $\begin{array}{l}\text { PUC - Pontifícia Universidade Católica - Rio } \\
\text { UDESC - Universidade do Estado de Santa } \\
\text { Catarina }\end{array}$ & $\begin{array}{l}\text { Introdução à Teoria Econômica } \\
\text { Mercado Financeiro e de Capitais }\end{array}$ \\
\hline UFJF - Universidade Federal de Juiz de Fora & $\begin{array}{l}\text { Economia } \\
\text { Microeconomia }\end{array}$ \\
\hline UFMG - Universidade Federal de Minas Gerais & $\begin{array}{l}\text { Economia A1 } \\
\text { Economia Industrial }\end{array}$ \\
\hline UFOP- Universidade Federal de Ouro Preto & Princípios de Economia \\
\hline UFRJ - Universidade Federal do Rio de Janeiro & Introdução à Economia \\
\hline UFSC - Universidade Federal de Santa Catarina & $\begin{array}{l}\text { Economia e Organização Industrial } \\
\text { Modelos Econômicos e Quantitativos }\end{array}$ \\
\hline UFSCar - Universidade Federal de São Carlos & $\begin{array}{l}\text { Introdução à Economia } \\
\text { Microeconomia }\end{array}$ \\
\hline UNESP - Universidade Estadual Paulista & $\begin{array}{l}\text { Economia } \\
\text { História Econômica Geral }\end{array}$ \\
\hline UNIFEI - Universidade Federal de Itajubá & Economia \\
\hline UNITAU - Universidade de Taubaté & $\begin{array}{l}\text { Economia Aplicada à Produção } \\
\text { Engenharia Econômica } \\
\text { Princípios de Economia Industrial }\end{array}$ \\
\hline $\begin{array}{l}\text { USP - Escola de Engenharia de São Carlos } \\
\text { USP - Universidade de São Paulo }\end{array}$ & $\begin{array}{l}\text { Fundamentos de Economia } \\
\text { Economia de Empresas } \\
\text { Economia e Engenharia Econômica } \\
\text { Economia Geral } \\
\text { Introdução à Economia }\end{array}$ \\
\hline
\end{tabular}

Fonte: Dados da pesquisa

Para a codificação e análise dos dados foi utilizado o software AnSWR, um programa de código aberto e, portanto, de domínio público. Esse programa, tendo-se inserido os dados e terminado o processo de codificação, permite a geração de diversos relatórios contendo, por exemplo, o cruzamento dos dados que caracterizam cada curso e disciplina, como cargas horárias e período em que são oferecidas. Por fim, após a sistematização e tratamento dos dados, procedeu-se a sua interpretação e análise quanto aos objetivos da pesquisa.

\section{RESULTADOS E DISCUSSÃO}

Os objetivos das disciplinas foram analisados em relação às competências identificadas na Taxonomia de Bloom e estão relacionados no Quadro 3. Do conjunto 
de objetivos observados, $68 \%$ correspondem à competência denominada "compreensão". Ou seja, $68 \%$ do trabalho efetuado nas disciplinas têm por objetivo levar o aluno a compreender os conceitos, demonstrando que entende a informação, compreende o significado de um conceito ou termo e interpreta fatos.

Quadro 3 - Lista de objetivos das disciplinas de Economia

\begin{tabular}{|lcc|}
\hline \multicolumn{1}{|c}{ Objetivos } & $\begin{array}{c}\text { Freqüências } \\
(\%)\end{array}$ & $\begin{array}{c}\text { Competência } \\
\text { (Taxonomia de } \\
\text { Bloom) }\end{array}$ \\
Proporcionar conhecimentos básicos & 31,58 & Conhecimento \\
Analisar a conjuntura econômica & 15,79 & Análise \\
Compreender conceitos da teoria econômica & 15,79 & Compreensão \\
Capacitar os alunos nos fundamentos da teoria & 13,16 & Compreensão \\
Analisar problemas econômicos & 5,26 & Análise \\
Estimular a capacidade crítica dos alunos & 5,26 & Análise \\
Estudar conceitos da teoria & 5,26 & Compreensão \\
Identificar problemas econômicos & 5,26 & Análise \\
Discutir os conceitos apresentados & 2,63 & Compreensão \\
\hline
\end{tabular}

Fonte: Dados da Pesquisa

O item de maior freqüência em relação ao conjunto de objetivos mencionados é "proporcionar conhecimentos básicos", que representa $31,58 \%$ dos objetivos. De fato, pode-se esperar que uma disciplina de Economia, ministrada em cursos de Engenharia de Produção, objetive a aquisição de conhecimentos básicos por parte dos estudantes, uma vez que há limitação de tempo e, conseqüentemente, há que se priorizar os tópicos essenciais, garantindo ao futuro engenheiro pelo menos uma visão geral do campo da economia. Porém, não há um aprofundamento dos conceitos abordados na disciplina.

A outra competência da Taxonomia de Bloom identificada nos objetivos, a "análise", equivale a $32 \%$ do esforço empregado nas disciplinas. Entende-se que esta competência é demonstrada quando o aluno mostra que pode reconhecer padrões, perceber significados ocultos e identificar componentes. Trata-se de uma habilidade mais elaborada que a compreensão, envolvendo "analisar", "explicar", "conectar", "comparar", "selecionar" e "inferir".

Quanto aos objetivos associados à competência "análise" destacam-se três, pois remetem ao conhecimento da realidade e contexto econômico: "analisar a 
conjuntura econômica", correspondendo a 15,79\%; "analisar problemas econômicos" e "identificar problemas econômicos", ambos com 5,26\%. Algumas frases retiradas dos planos ajudam a clarificar os objetivos declarados para estas disciplinas, em relação à competência "análise", sendo interessante notar que estão associados à análise do cenário econômico brasileiro atual:

"... contribuir com o entendimento do cenário econômico do País".

"Elaborar elementos analíticos que permitam análises de conjuntura do cenário econômico brasileiro atual'.

"...que os alunos acompanhem e analisem a conjuntura econômica nacional e mundial'.

As estratégias de ensino utilizadas foram sintetizadas no Quadro $4 \mathrm{e}$ correspondem ao relatado por LUQUE E MACHUCA (2003), pelo menos no que diz respeito à de maior freqüência neste conjunto - a aula expositiva, citada em 43,58\% dos planos. Pode-se supor que, apesar de não serem citadas nos planos, as aulas expositivas são utilizadas na totalidade das disciplinas, o que estaria de acordo com Becker (2003). Segundo esse autor, o estereótipo do professor de economia nos Estados Unidos é aquele que conduz uma exposição para seus alunos, à medida que escreve textos, equações e gráficos no quadro e passa leituras para serem feitas pelos alunos em seus livros-textos.

Além disso, no Brasil, de acordo com Pinto et al. (2004), a prática tradicional de ensino usada majoritariamente nas escolas de engenharia do país, é baseada na concepção de que o conhecimento é transmitido por meio de aulas expositivas e seu aprendizado verificado por meio de provas. Para esses autores, essa abordagem, consolidada em meados do século passado e que se constituiu em um avanço para as sociedades da época, hoje não é mais capaz de produzir as respostas socialmente demandadas. De acordo com esses autores, experiências têm sido realizadas, quase sempre de maneira individual e desarticulada, no sentido de tentar melhorar a qualidade do ensino de engenharia e, embora alguns resultados positivos tenham sido alcançados, não se chegou à formulação de alternativas ao modelo atual.

A estratégia "apresentações por parte dos alunos", com 15,38\% do total, corresponde às apresentações que os alunos desenvolvem e realizam, com ou sem 
apartes do professor, sobre um texto pré-definido ou capítulos do livro-texto adotado, não envolvendo, necessariamente, o trabalho de pesquisa por parte dos alunos.

Quadro 4 - Estratégias de Ensino das disciplinas de Economia

\begin{tabular}{|lc|}
\hline \multicolumn{1}{|c}{ Estratégias de Ensino } & Freqüência (\%) \\
Aulas expositivas & 43,58 \\
Apresentações por parte dos alunos & 15.38 \\
Resolução de exercícios em sala de aula & 12.82 \\
Elaboração de textos em sala de aula & 10.26 \\
Debates entre os alunos & 7.69 \\
Dinâmicas de grupos & 7.69 \\
Utilização de laboratório de informática & 5.13 \\
Leitura de artigos científicos & 2.56 \\
Leitura de bibliografias indicadas & 2.56 \\
Leitura de jornais e/ou revistas & 2.56 \\
Utilização de vídeos & 2.56 \\
\hline
\end{tabular}

Fonte: Dados da Pesquisa

As estratégias "debates entre os alunos" e "dinâmicas de grupos", com 7,69\% cada, aparecem com uma baixa freqüência de utilização. Elas correspondem à realização de atividades que envolvam a discussão, de forma oral, de temas préselecionados ou a vivência de alguma situação, para as quais os alunos devem se preparar previamente. Conforme sugerido por Ghisi et al. (2001), estas atividades deveriam valorizar mais a externalização das opiniões dos alunos, com base em sua reflexão, do que a exposição de conteúdos ou históricos.

Já as estratégias de leituras indicadas nos Planos de Ensino são relativas a três tipos diferentes de materiais: artigos científicos especializados, bibliografia básica e complementar, jornais e revistas. A freqüência de cada uma é $2,56 \%$, sendo, portanto, das menos utilizadas. Conforme sugerido na literatura (BELHOT, 2005; GHISI et al., 2001), essas estratégias de leituras poderiam ser combinadas com as discussões ou debates entre os alunos, por terem o potencial de expô-los às diferentes visões ou perspectivas em relação aos tópicos apresentados. Ou, ainda, à elaboração de relatórios e/ou fichamentos de leitura, que poderiam culminar com a elaboração de artigos científicos. Rezende (2005) descreveu sua experiência bem- 
sucedida na utilização desta estratégia, ressaltando que houve uma melhora na habilidade de escrita, na análise crítica dos textos e na utilização da terminologia apropriada, resultando em melhoria na interpretação dos fatos econômicos. Houve, também, conforme relato desse autor, utilização de informações que estavam além do que havia sido proposto como mínimo de leitura.

A pouca utilização de jornais e/ou revistas, em especial, pode estar ligada a pouca ênfase dada ao objetivo "análise da conjuntura econômica". Uma vez que, conforme apresentado anteriormente, a estratégia mais utilizada é a da aula expositiva, pode-se concluir que a construção do conhecimento nas disciplinas é bastante dependente do professor, com participação limitada dos alunos neste processo. Essa estratégia é condizente com o objetivo "Proporcionar conhecimentos básicos" citado em $31,58 \%$ dos planos.

A estratégia de "utilização de laboratório de informática" corresponde a 5,13\% do conjunto de estratégias apontadas nos Planos de Ensino. Esta estratégia pode incluir a utilização de softwares específicos para o ensino de economia, planilhas de cálculos ou pacotes estatísticos, incluindo-se também a utilização do computador para pesquisas na internet. Entretanto, não é possível concluir-se sobre as razões para a baixa utilização deste recurso somente com os dados dos planos de ensino.

O Quadro 5 relaciona os conteúdos ministrados nas disciplinas de acordo com os planos de ensino. Os conteúdos mais trabalhados nos cursos analisados são aqueles que possuem maior identificação com a Engenharia de Produção. Deste modo, a Microeconomia aparece em primeiro lugar, com 23,66\% do conjunto de conteúdos analisados para os cursos selecionados. Deve-se lembrar que existem duas universidades com disciplinas específicas de Microeconomia (Quadro 2). Já a Macroeconomia corresponde a $22,58 \%$ do total de conteúdos mencionados nos Planos de Ensino. Estas duas grandes áreas da Teoria Econômica correspondem, portanto a, aproximadamente, $46 \%$ do total dos conteúdos trabalhados nos cursos de Engenharia de Produção abordados nesta pesquisa. Dada esta importância, estes conteúdos foram desdobrados conforme detalhamentos encontrados nos Planos de Ensino. 
Quadro 5 - Lista de conteúdos das disciplinas de Economia

\begin{tabular}{|lc|}
\hline \multicolumn{1}{c}{ Conteúdos } & Freqüência (\%) \\
Microeconomia & 23.66 \\
Macroeconomia & 22.58 \\
Conceitos básicos & 16.13 \\
História do Pensamento Econômico & 8.6 \\
Contabilidade social & 7.53 \\
Economia Brasileira & 6.45 \\
Economia Internacional & 6.45 \\
Economia Monetária & 5.38 \\
Desenvolvimento Econômico & 3.23 \\
\hline
\end{tabular}

Fonte: Dados da Pesquisa

$\mathrm{Na}$ Microeconomia notou-se que há maior ênfase para a Teoria da Firma (31,71\% dos planos de ensino), assunto facilmente associado com a Engenharia de Produção, uma vez que as funções de produção e a maximização de resultados, por exemplo, são abordadas nessa área. O estudo da atuação das empresas e a forma como os recursos produtivos são alocados, também são abordados na Teoria da Firma e facilmente associados às necessidades dos engenheiros de produção. Outros assuntos abordados são: Mercado de Bens (24,39\%), Escolha Individual (14,63\%) e Mercados de Recursos e Equilíbrio Geral (12,2\%).

$\mathrm{Na}$ Macroeconomia cerca de $80 \%$ do conteúdo divide-se equitativamente entre os tópicos de Introdução à Macroeconomia, Modelos Macroeconômicos e Política Econômica. Os dois primeiros são tópicos que apresentam grande conteúdo teórico, que normalmente recebe tratamento matemático e gráfico, o que certamente os torna mais palatáveis para o estudante de Engenharia de Produção, sobretudo quando tais conteúdos são oferecidos mais tardiamente nas grades curriculares dos cursos, o que, de fato, acontece, nos cursos estudados pela presente pesquisa.

Para a análise da categoria "conteúdos básicos", três situações diferentes foram consideradas. Em primeiro lugar, a existência de apenas uma disciplina no curso - nestes casos, uma parte do conteúdo aborda tópicos introdutórios, enquanto outra parte é dedicada às diferentes áreas da economia, especialmente Microeconomia e Macroeconomia. Outra situação ocorre no caso da existência de mais de uma disciplina, dentre as quais uma funcionando como disciplina 
introdutória (independentemente de ser ou não pré-requisito). Por fim, a existência de tópicos de introdução geral em disciplinas específicas (tais como Macroeconomia ou Microeconomia). Das 28 disciplinas selecionadas e listadas no Quadro 2, 14 abordam os "conceitos básicos" da Economia, que totalizam 16,33\% de todos os conteúdos abordados. Nesta categoria estão incluídos itens como: o problema fundamental da economia; oferta e demanda; diferenças entre microeconomia e macroeconomia; curva de possibilidades de produção; caracterização da ciência econômica; natureza e método da economia; divisões da economia; economia capitalista e socialismo e capitalismo. Não foram incluídos nesta categoria os tópicos introdutórios pertencentes às áreas específicas, como a Contabilidade Social, Macroeconomia ou Microeconomia. Chama a atenção o fato de quatro instituições não mencionarem estes conteúdos em seus Planos de Ensino. Entretanto, não se pode afirmar que tais conteúdos não sejam contemplados nestas disciplinas.

Verificou-se também que aproximadamente $38 \%$ do total dos conteúdos é dedicado às demais divisões da Economia. A categoria "História do Pensamento Econômico" corresponde a 8,6\% dos conteúdos e identifica as menções feitas nos Planos de Ensino a tópicos como: história do pensamento econômico; evolução do pensamento econômico; linhas de formação da economia capitalista; escolas e doutrinas econômicas; diferentes escolas de pensamento. Dentre as instituições analisadas, apenas 6 mencionaram este conteúdo, que compõe o programa de 8 disciplinas. É importante salientar que este conteúdo é coberto por uma disciplina exclusiva em uma das instituições.

Quanto à categoria "Contabilidade Social", optou-se por seguir a classificação encontrada em Calveti (2002), que a considera no grupo de disciplinas que possuem um caráter eminentemente prático, diferenciando-se dos autores que consideram a Contabilidade Social como integrante da disciplina Macroeconomia. Sendo assim, foram consideradas as menções existentes à Contabilidade Social nos Planos de Ensino das diversas disciplinas analisadas nesta pesquisa, identificando-se uma participação de $7,53 \%$ no total dos conteúdos. Este tópico também é trabalhado por 8 disciplinas, em apenas 6 instituições.

As categorias "Economia Brasileira" e "Economia Internacional" representam, cada uma, 6,45\% do total dos conteúdos. Junto com a "Contabilidade Social", estas três categorias representam pouco mais de $20 \%$ dos conteúdos. Fazendo-se um 
cruzamento destas categorias com as instituições de ensino que as incluem em seus cursos, observou-se que apenas uma apresenta todas elas em seu Planos de Ensino. Apenas duas instituições mencionam "Economia Internacional" e "Contabilidade Social" em seus planos. As demais apresentam apenas uma das três categorias e em três instituições nenhum destes tópicos é mencionado nos planos de ensino.

A Economia Brasileira apresenta um conteúdo de caráter mais filosóficohistórico do que teórico-matemático, que pressupõe a necessidade de maior contextualização dos fatos atuais para que sua compreensão e análise sejam mais consistentes. Para ilustrar, pode-se citar o estudo do quadro de estabilidade econômica que se tem experimentado no Brasil, sobretudo nestes últimos dois anos. Suas raízes podem ser encontradas na implantação do Plano Real, na década de 90, que por sua vez foi ensejado diante do quadro de alta inflação e de sucessivos planos de estabilização anteriores, gestados a partir da segunda metade da década de 80.

Não é possível afirmar que tais conteúdos não são apresentados durante as aulas das disciplinas ligadas à economia nas diferentes instituições apenas com os dados trabalhados nesta pesquisa, pois podem vir a ser abordados por meio de exemplos e contextualizações das teorias. Contudo, se fossem documentados nos Planos de Ensino, seria uma situação mais próxima da ideal, pois, conforme salientado por Fusari (1998), tal prática serviria como uma orientação mais precisa para o trabalho docente. Ademais, seria oportuna a introdução de temas transversais para os alunos no transcorrer destas disciplinas, pois questões sociais poderiam ser colocadas para a reflexão dos alunos, favorecendo o desenvolvimento da capacidade de se posicionar sobre a realidade brasileira e mundial, conforme pontuado por Stinghem (2001) e contribuindo para sua formação cidadã.

Foram identificados mais dois conteúdos trabalhados nos cursos de Engenharia de Produção que apresentaram freqüência de 5,38\% e 3,23\%, respectivamente - "Economia Monetária" e "Desenvolvimento Econômico". Conforme apresentado no referencial teórico, tais conteúdos se inserem no que Calveti (2002) identificou como a abordagem prática da economia, que se refere a tópicos mais específicos - sobretudo a Economia Monetária. Observou-se que apenas três instituições prevêem em seus Planos de Ensino o tópico 
"Desenvolvimento Econômico". Novamente, não é possível afirmar que estes tópicos não são abordados em outras instituições apenas baseando-se nos dados da pesquisa. Seria interessante, porém, que fosse refletida nos Planos de Ensino a possibilidade de se combinar a abordagem da Microeconomia sobre os Mercados de Bens, os Mercados de Recursos, com estudos sobre os Arranjos Produtivos Locais e as implicações para o Desenvolvimento Econômico, por exemplo. O tópico Economia Monetária pode também estar sendo abordado dentro do assunto Política Econômica, uma vez que estão fortemente relacionados. Entretanto, não foi possível perceber essa possibilidade pelos planos de ensino analisados. Na discussão dos resultados quanto aos objetivos das disciplinas foi mencionado que os objetivos ligados à competência "análise" diziam respeito à conjuntura econômica atual, inclusive a doméstica. Mas, como foi possível notar, pouca ênfase é dada aos conteúdos que trabalham estes contextos.

Novas dúvidas sobre a forma como é abordada a conjuntura econômica atual, principalmente a nacional, podem ser levantadas na análise da bibliografia sugerida para as disciplinas. Essa análise demonstrou que há uma grande dispersão das referências bibliográficas utilizadas nas disciplinas, ou seja, existe uma grande diversidade de livros sendo utilizados nas instituições pesquisadas. Portanto, não foram encontradas referências bibliográficas que possam ser consideradas típicas para cada tópico da Economia.

Constatou-se que apenas 6 autores aparecem como os mais indicados, 24 possuem duas indicações e os demais 27 , uma indicação apenas, o que equivale a menos de $1 \%$ de freqüência relativa. O quadro 6 apresenta os autores com as maiores freqüências.

A pouca ênfase dada à análise da conjuntura econômica atual ou à Economia Brasileira é reforçada pela constatação de que um dos autores mais citado, N. G. Mankiw, não apresenta em seus livros exemplos da conjuntura brasileira (MANKIW, 2001). Essa situação se repete nos demais autores citados no Quadro 6, exceto em Vasconcellos (2002) e no livro da Equipe de Professores da USP (PINHO e VASCONCELLOS, 2004), que oferecem alguns poucos exemplos ou tópicos específicos sobre a economia brasileira. 
Quadro 6 - Principais autores indicados como bibliografia básica nos planos de ensino

\begin{tabular}{|lcc|}
\hline Autor & $\begin{array}{c}\text { Número de } \\
\text { indicações }\end{array}$ & $\begin{array}{c}\text { Freqüência (\% em relação ao } \\
\text { número total de livros indicados) }\end{array}$ \\
MANKIW & 7 & 6.14 \\
VASCONCELLOS & 7 & 6.14 \\
EQUIPE DE & 6 & 5.26 \\
PROFESSORES DA USP & & \\
FERGUSON & 3 & 2.63 \\
HUNT & 3 & 2.63 \\
VARIAN & 3 & 2.63 \\
\hline
\end{tabular}

Fonte: Dados da Pesquisa

Cabe aqui levantar dois pontos para uma reflexão mais ampla. Primeiramente, chamou a atenção o fato de haver vasta e diferenciada indicação de bibliografia para cada disciplina e, ao mesmo tempo, não ser tão explorada a utilização de leituras em geral e, mais especificamente, de leitura de bibliografia indicada, conforme foi pontuado na análise das Estratégias de Ensino. Luque e Machuca (2003) também reportaram situação análoga em sua pesquisa, na qual constataram haver um predomínio da tradicional estratégia da aula expositiva. Discorrendo sobre as possíveis causas, eles apontaram a existência de classes com muitos alunos e a grande expansão do conteúdo dos cursos, com o aumento dos tópicos de interesse e o limitado número de horas disponíveis.

O último aspecto que foi analisado em relação aos Planos de Ensino diz respeito às estratégias de avaliação do desempenho dos alunos, sintetizados no Quadro 7. Da mesma maneira que Luque e Machuca (2003) constataram em seu estudo, foi possível verificar que a estratégia de maior utilização é a prova escrita, utilizada em quase a totalidade dos casos. Em 38\% das disciplinas essa é a única forma de avaliação. A avaliação também é feita combinando-se a prova escrita com uma ou mais estratégias. 
Quadro 7 - Frequência das formas de avaliação mencionadas para as disciplinas de Economia

\begin{tabular}{|lc|}
\hline \multicolumn{1}{|c|}{ AVALIAÇÃO } & Freqüência (\%) $^{\star}$ \\
Prova & 98.1 \\
Apresentação de Seminários & 14.29 \\
Trabalhos em grupo & 11.9 \\
Trabalhos individuais & 11.9 \\
Resolução de Exercício(s) valendo nota & 9.52 \\
Instrumento de avaliação não especficado & 7.14 \\
Participação em sala & 4.76 \\
Submissão de Relatório de pesquisa / leitura & 2.38
\end{tabular}

Fonte: Dados da Pesquisa

Identificou-se que a segunda estratégia mais utilizada é a "apresentação de seminários", com aproximadamente 14\%. A resolução de exercícios em sala de aula também é uma maneira utilizada para avaliar os alunos, apresentando-se com aproximadamente $10 \%$ das estratégias, não sendo, portanto, muito utilizada. Nos Planos de Ensino, sua utilização recebe indicação individual ou em dupla, em alguns casos, o que tende a favorecer o diálogo e a discussão. Em um dos planos há a indicação de que os exercícios valem como tarefa extra-classe e são os retirados da bibliografia básica.

Notou-se que cerca de $7 \%$ das estratégias de avaliação correspondem à categoria "instrumentos não especificados". Foram codificadas nesta categoria as menções vagas, tais como: "avaliações intermediárias", "média de três notas", "três notas distribuídas ao longo do semestre".

A estratégia de avaliar a participação em sala de aula é pouco utilizada, talvez devido à subjetividade deste conceito. Igualmente, pouca ênfase é dada aos relatórios de pesquisa ou relatório de leitura, o que poderia comprometer o desenvolvimento da competência de interpretação de textos, e até mesmo a construção do perfil desejado para o egresso de um curso de Engenharia, que deve possuir formação generalista, humanista, crítica e reflexiva, conforme dispõe a Resolução CNE/CES 11/2002 (BRASIL, 2002). 


\section{CONCLUSÕES}

Esta pesquisa teve como objetivo analisar o ensino de Economia nos cursos de Engenharia de Produção, trabalhando os aspectos referentes ao currículo, como o conteúdo das disciplinas, as cargas horárias, as estratégias utilizadas durante a condução das disciplinas para o ensino e avaliação dos alunos. Existe atualmente uma preocupação em se refletir sobre as mudanças ocorridas nos cursos de Engenharia de Produção, tanto pela imposição legal quanto pela percepção de que há um novo paradigma alternativo ao sistema mecanicista ainda prevalente, apesar de esta preocupação não ser facilmente generalizada. $O$ ensino da Teoria Econômica é de particular interesse, pois seu conteúdo se inter-relaciona com as questões com as quais um Engenheiro de Produção irá freqüentemente se deparar.

Embora os conteúdos trabalhados sejam abrangentes, a forma de trabalhálos, bem como a maneira como os alunos são avaliados, ainda é de caráter tradicional. Percebeu-se que há uma grande necessidade de se articular os saberes teóricos com a realidade, o que poderia ser alcançado com uma maior ênfase aos conteúdos de Economia Brasileira e Economia Internacional, por meio de projetos extra-classe e da utilização de veículos de comunicação que possibilitem trazer a realidade cotidiana para a sala de aula. Pelo fato de a pesquisa se limitar aos registros dos Planos de Ensino, não foi possível diagnosticar as práticas docentes não registradas por escrito que, como salientou Fusari (1998), devem extrapolar as habilidades mínimas exigidas para a execução do planejamento de ensino.

Outro ponto a ser sublinhado é o fato de o objetivo desta pesquisa ser de caráter exploratório, tendo como forte característica o levantamento de questões que necessitarão de maiores esclarecimentos futuros. Assim, os questionamentos apontados na análise dos resultados desta pesquisa devem ser recomendados à investigação em trabalhos que venham ser desenvolvidos futuramente. Sintetizando tais questionamentos, são apresentados abaixo alguns pontos que poderão ser investigados futuramente. Devem ser buscados esclarecimentos sobre a relação entre carga horária das disciplinas em relação à carga horária dos cursos. Quanto aos aspectos didáticos, esclarecer a pouca utilização de jornais e revistas, bem como a pouca exploração de leituras em geral e, mais especificamente, indicações de leituras da bibliografia sugerida. 
Outros pontos a serem investigados em trabalhos futuros: como é feita a abordagem dos conteúdos introdutórios em instituições que não apresentam disciplinas específicas de introdução (por exemplo, Introdução à Economia); o porquê da pouca ênfase dada aos tópicos 'Economia Brasileira' e 'Desenvolvimento Econômico nos cursos de Engenharia de Produção.

Finalmente, deve ser investigada a maneira como os conteúdos relativos à conjuntura econômica doméstica são trabalhados, uma vez que a bibliografia sugerida parece não favorecer tal situação e há, ao mesmo tempo, baixa utilização de jornais e revistas.

\section{REFERÊNCIAS}

BECKER, W. E., HAMILTON, J., HOYT, G. M. e McMILLIN, W. D. Economics: the sexy social science?. Southern Economic Journal, p. 195-225, 2003.

BELHOT, R. V. A didática no ensino de engenharia. In: CONGRESSO BRASILEIRO DE ENSINO DE ENGENHARIA - COBENGE.33, 2005. Anais... Campina Grande, 2005.

BRASIL. Resolução CNE/CES 11/2002, de 11 de março de 2002. Institui as diretrizes curriculares do curso de graduação em engenharia. Disponível em: < http://portal.mec.gov.br/cne/arquivos/pdf/CES112002.pdf >. Acesso em: $14 \mathrm{de}$ fev. 2008.

CALVETI, C. Investigação econômica e ciência econômica: técnicas de pesquisa em economia: transformando curiosidade em conhecimento. São Paulo: Saraiva, 2002. $408 \mathrm{p}$.

CORTES, in: Bêrni, D de A. (Org.). Técnicas de pesquisa em economia: transformando curiosidade em conhecimento. São Paulo: Saraiva, 2002. 408 p.

DIEHL, A. A. e TATIM, D. C. Pesquisa em ciências sociais aplicadas: métodos e técnicas. São Paulo: Pearson Prentice Hall, 2004. 168 p.

FOLHA DE SÃO PAULO. Unicamp segue USP e decide ficar fora do Enade. Disponível em: < http://www1.folha.uol.com.br/folha/educacao/ult305u16055.shtml >. Acesso em: 07 ago. 2008.

FUSARI, J. C. O planejamento do trabalho pedagógico: algumas indagações e tentativas de respostas. Série Ideias, n. 8. P. 44-53, 1998.

GHISI, F. A., PIMENTA JUNIOR, T. e FAMÁ, R. Uma estratégia didática para o ensino de economia e finanças internacionais. SEMINÁRIO EM ADMINISTRAÇÃO - SEMEAD, 5, 2001. Anais.... São Paulo, 2001. 
INEP. ENADE 2005: Relatório Síntese - Área de Engenharia Grupo VI. Brasília, DF, Brasil: 2005. Disponível em < www.inep.gov.br >. Acesso em 12 abr. 2008.

LUQUE, R. A. e MACHUCA, J. A. D. An empirical study of POM teaching in Spanish Universities (II): faculty profile, teaching and assessment methods. International Journal of Operations \& Production Management, v.23, n.4, p. 375-400, 2003.

MANKIW, N. G. Introdução à economia. 2 ed. Rio de Janeiro: Campus, 2001.

MARCONI, M. de A. e LAKATOS, E. M. Técnicas de pesquisa. São Paulo: Atlas, 1999. $260 \mathrm{p}$.

PINTO, D. P., PORTELA, J. C. da S. e SILVEIRA, M. H. Currículo e projeto pedagógico. SIMPEP, 11, 2004. Anais... Bauru, SP, 2004.

PIRATELLI, C. L. A engenharia de produção no Brasil. In: CONGRESSO BRASILEIRO DE ENSINO DE ENGENHARIA - COBENGE. 33, 2005. Anais... Campina Grande, 2005.

PINHO, D. B.; VASCONCELLOS, M. A. S. Manual de economia. São Paulo: Saraiva, 2004.

REZENDE, M. L. Relato de experiência. Disponível em: < http://www.prg.unifei.edu.br/oficina/Relatos/rel001.htm >. Acesso em: 02 set. 2008.

STINGHEN, F. M. A inserção dos temas transversais no currículo escolar através do uso da internet. 2001. 167f. Dissertação (Mestrado) - Programa de Pós Graduação em Engenharia de Produção Florianópolis: Universidade Federal de Santa Catarina - UFSC. Florianópolis, 2001.

VASCONCELOS, M. A. S. Economia: micro e macro. São Paulo: Atlas, 2002.

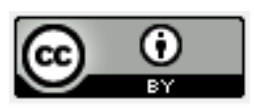

Artigo recebido em 17/02/2011 e aceito para publicação em 20/12/2011. 